\title{
Pre- and perinatal hypoxia associated with hippocampus/amygdala volume in bipolar disorder
}

\author{
U. K. Haukvik ${ }^{1,2 *}$, T. McNeil ${ }^{3,4}$, E. H. Lange ${ }^{1,2}$, I. Melle ${ }^{2,5}$, A. M. Dale ${ }^{6,7}$, \\ O. A. Andreassen ${ }^{2,5}$ and I. Agartz ${ }^{1,2}$ \\ ${ }^{1}$ Department of Psychiatric Research, Diakonhjemmet Hospital, Oslo, Norway \\ ${ }^{2}$ K. G. Jebsen Centre for Psychosis Research, Institute of Clinical Medicine, University of Oslo, Oslo, Norway \\ ${ }^{3}$ Department of Psychiatric Epidemiology, Lund University, Lund, Sweden \\ ${ }^{4}$ School of Psychiatry and Clinical Neurosciences, University of Western Australia, Perth, WA, Australia \\ ${ }^{5}$ K. G. Jebsen Centre for Psychosis Research, Division of Mental Health and Addiction, Oslo University Hospital, Oslo, Norway \\ ${ }^{6}$ Department of Neurosciences, University of California San Diego, La Jolla, CA, USA \\ ${ }^{7}$ Department of Radiology, University of California San Diego, La Jolla, CA, USA
}

Background. Pre- and perinatal adversities may increase the risk for schizophrenia and bipolar disorder. Hypoxiarelated obstetric complications (OCs) are associated with brain anatomical abnormalities in schizophrenia, but their association with brain anatomy variation in bipolar disorder is unknown.

Method. Magnetic resonance imaging brain scans, clinical examinations and data from the Medical Birth Registry of Norway were obtained for 219 adults, including 79 patients with a DSM-IV diagnosis of bipolar disorder (age 29.4 years, S.D. $=11.8$ years, $39 \%$ male) and 140 healthy controls (age 30.8 years, s.D. $=12.0$ years, 53\% male). Severe hypoxia-related OCs throughout pregnancy/birth and perinatal asphyxia were each studied in relation to $a$ priori selected brain volumes (hippocampus, lateral ventricles and amygdala, obtained with FreeSurfer), using linear regression models covarying for age, sex, medication use and intracranial volume. Multiple comparison adjustment was applied.

Results. Perinatal asphyxia was associated with smaller left amygdala volume $(t=-2.59, p=0.012)$ in bipolar disorder patients, but not in healthy controls. Patients with psychotic bipolar disorder showed distinct associations between perinatal asphyxia and smaller left amygdala volume $(t=-2.69, p=0.010)$, whereas patients with non-psychotic bipolar disorder showed smaller right hippocampal volumes related to both perinatal asphyxia $(t=-2.60, p=0.015)$ and severe OCs $(t=-3.25, p=0.003)$. No associations between asphyxia or severe OCs and the lateral ventricles were found.

Conclusions. Pre- and perinatal hypoxia-related OCs are related to brain morphometry in bipolar disorder in adulthood, with specific patterns in patients with psychotic versus non-psychotic illness.

Received 11 March 2013; Revised 29 May 2013; Accepted 30 May 2013; First published online 27 June 2013

Key words: MRI, neurodevelopment, neuroimaging, obstetric complications, psychosis.

\section{Introduction}

The exact pathophysiology and aetiology of the severe mental disorders schizophrenia and bipolar disorder remain unknown. They have been hypothesized to be part of the same psychosis continuum, since they in addition to overlapping symptoms share some genetic underpinnings (Purcell et al. 2009), cognitive impairments (Simonsen et al. 2011) and brain anatomical abnormalities (Ellison-Wright \& Bullmore, 2010). Whereas pre- and perinatal complications have been established as risk factors for schizophrenia (Fatemi \& Folsom, 2009; Rapoport et al. 2012), the evidence

\footnotetext{
* Address for correspondence: U. K. Haukvik, M.D., Ph.D., Department of Psychiatric Research, Diakonhjemmet Hospital, PO Box 85 Vinderen, 0319 Oslo, Norway.

(Email: unn.haukvik@medisin.uio.no)
}

for an association between pre- and perinatal adversities and the risk for bipolar disorder is less consistent. Some authors have argued that in genetically susceptible individuals, the absence of pre- and perinatal complications favours the development of bipolar disorder whereas their presence favours the development of schizophrenia (Murray et al. 2004; Demjaha et al. 2012).

Nevertheless, some epidemiological studies suggest that pre- and perinatal factors may increase the risk for bipolar disorder and affective psychosis. Hultman et al. (1999) have demonstrated an association between specific obstetric complications (OCs) and affective psychosis; an increasing birth weight was found to linearly associate with decreased risk for affective disorders (Abel et al. 2010); recently, increased risk for bipolar disorder in children born pre-term [odds ratio 2.7, 95\% confidence interval (CI) 1.6-4.5] was reported 
(Nosarti et al. 2012). Accordingly, neurodevelopmental disturbances and/or pre- and perinatal trauma may also be of importance for the development of bipolar disorder.

Magnetic resonance imaging (MRI) studies have demonstrated the existence of neuroanatomical abnormalities in bipolar disorder (Hallahan et al. 2011), the most consistent finding being enlarged ventricular volumes (Kempton et al. 2008; Arnone et al. 2009; Rimol et al. 2010; Hallahan et al. 2011). The results for other brain structures differ among studies, possibly due to low sample sizes and confounding factors, such as lithium medication. Recent meta-analyses report that lithium-naive patients with bipolar disorder have smaller hippocampal and amygdala volumes as compared with patients who receive lithium medication and with healthy controls (Hallahan et al. 2011; Hajek et al. 2012). There is also some evidence supporting more pronounced brain abnormalities in patients with psychotic bipolar disorder than in patients with non-psychotic disorder (Strasser et al. 2005; Edmiston et al. 2011; Anticevic et al. 2013). The mechanisms underlying the structural brain abnormalities observed in bipolar disorder are not completely known. Post-mortem studies have demonstrated reduced neural somal size (Bezchlibnyk et al. 2007) and neuron numbers (Berretta et al. 2007) in the amygdala, and reduced number of parvalbumin- and somatostatin-expressing interneurons (Konradi et al. 2011) and reduced pyramidal cell size (Liu et al. 2007; Konradi et al. 2011) in the hippocampus of bipolar disorder patients. These neuronal changes may have a developmental origin, given the fact that animal models have demonstrated long-term neuronal loss in the amygdala (Carty et al. 2010) and reduced pyramidal cell size in the hippocampus (Rees et al. 2008) following pre- and perinatal hypoxia. Moreover, smaller hippocampal volumes and larger ventricular volumes have been demonstrated in schizophrenia patients with a history of pre- and perinatal hypoxia (Cannon et al. 2002; van Erp et al. 2002). Enlarged ventricles have also been observed in schizophrenia patients who suffered prolonged birth (indicating hypoxia) (McNeil et al. 2000). In schizophrenia, smaller hippocampal volumes have been reported following OCs in general (Ebner et al. 2008), and severe OCs have been reported to interact with the hypoxiaregulated GRM3 (metabotropic glutamate receptor 3) gene to affect hippocampal volume (Haukvik et al. 2010). Smaller hippocampal volume and reduced grey matter have been observed in otherwise healthy subjects born very preterm (before week 33) (de Kieviet et al. 2012). Smaller hippocampal volume has also been reported in healthy adolescents following perinatal asphyxia (Maneru et al. 2003), and long-term reductions of the grey matter in the amygdala have been observed in children with neonatal hypoxiaischaemia (Peterson et al. 2000). Hence, it is plausible that pre- and perinatal complications affect brain structure abnormalities associated with bipolar disorder.

The aim of the current study was to investigate the relationship between pre- and perinatal trauma and brain structure volumes in patients with bipolar disorder. Specifically, we studied the relationship between two measures of pre/perinatal trauma [i.e. an established composite severe OCs score comprising complications occurring throughout the whole preand perinatal period (McNeil et al. 1994), and a diagnosis of perinatal asphyxia, a distinct complication shown by animal models to cause long-term brain abnormalities (Rees et al. 2008; Carty et al. 2010)], and three brain volumes either previously reported to be associated with OCs in schizophrenia (i.e. hippocampus and lateral ventricles) or associated with bipolar disorder (i.e. amygdala).

We hypothesized that perinatal asphyxia and severe OCs would be associated with smaller hippocampus and amygdala volumes, and with larger ventricular volumes, in patients with bipolar disorder, and that the associations would be stronger in those with psychotic than in those with non-psychotic disorder. This latter prediction is based on the findings of more pronounced brain abnormalities (Strasser et al. 2005; Edmiston et al. 2011; Anticevic et al. 2013) and cognitive impairments (Simonsen et al. 2011) in the psychotic than non-psychotic form of bipolar disorder. In addition, psychotic bipolar disorder may be more similar to schizophrenia, a disorder in which patients with OCs show more pronounced brain abnormalities than patients without such complications (McNeil et al. 2000; van Erp et al. 2002; Schulze et al. 2003, Ebner et al. 2008).

To our knowledge, this is the first study to explore the association between hypoxia-related OCs, in particular perinatal asphyxia, and neuroanatomy in bipolar disorder.

\section{Method}

\section{Subjects}

The subject sample $(n=219)$ consisted of patients with a Diagnostic and Statistical Manual of Mental Disorders, Fourth Edition (DSM-IV) diagnosis within the bipolar spectrum $(n=79)$ - bipolar I disorder (DSM-IV 296.0-7) $(n=47)$, bipolar II disorder (DSM-IV 296.89) $(n=28)$, or bipolar disorder not otherwise specified (DSM-IV 296.80) $(n=4)$ - and healthy controls $(n=140)$ from the ongoing multi-centre Thematically Organized Psychosis Study at the University of Oslo, Norway. 
All subjects were born in Norway and aged between 18 and 42 years at the start of the study.

Patients were included from four major psychiatric hospitals and their out-patient clinics that together cover most of the population in Oslo. All patients underwent thorough clinical investigation by specially trained psychologists and physicians. Clinical diagnoses were assessed using the Structured Clinical Interview for DSM-IV Axis I disorders (SCID-I) module A-E (Spitzer et al. 1988), with an overall agreement for diagnostic categories of $82 \%(\kappa=0.77,95 \% \mathrm{CI}$ $0.60-0.94)$. Psychosocial function was assessed with the Global Assessment of Function scale - split version. Affective state was assessed with the Young Mania Rating Scale and the Inventory of Depressive Symptomatology (IDS) scale. Current psychotic symptoms were rated by the use of the Positive and Negative Syndrome Scale (PANSS), with intraclass coefficients of 0.73 and 0.86 for the positive and negative subscales, respectively (Engh et al. 2010). Patients were classified as having psychotic $(n=48)$ or non-psychotic $(n=31)$ bipolar disorder based on the presence of current psychotic episode (defined as a score of 4 or above on any one of the PANSS items P1, P3, P5, P6, G9), or a history of psychosis based on information retrieved from the SCID-I interview.

The healthy control subjects were randomly selected from the national population register, and resident in the same catchment area as the patients. They were interviewed for symptoms of severe mental illness by trained psychologists and examined with the Primary Care Evaluation of Mental Disorders (Spitzer et al. 1994) to ensure no current or previous psychiatric disorders. Control subjects with current or previous somatic illness, or substance misuse disorder including alcohol overuse that could affect brain morphology were excluded. Demographic and clinical variables are listed in Table 1.

The study was approved by the Regional Committee for Medical Research Ethics and the Norwegian Data Inspectorate, and was conducted in accordance with the Helsinki declaration. After complete description of the study to the subjects, written informed consent was obtained from all participating subjects.

\section{Birth data}

The birth data were collected from the Medical Birth Registry of Norway (MBRN). In Norway, all births after gestational week 16 are compulsorily reported to the MBRN by the attending midwife or physician (Irgens, 2000). Medical and sociodemographic data pertaining to the pregnancy, birth, and the health of the mother and the newborn are recorded on a standardized notification form by the midwife or doctor who attend the birth and reported to the MBRN. This notification form has remained unchanged during the period in which all subjects in the current study were born (1967-1991). Based on the information from the MBRN, i.e. birth data from the mother and the health of the newborn (the patient), one physician (U.K.H.) who was blinded to patient/ control status scored presence and severity of OCs according to the McNeil-Sjöström scale (McNeil \& Sjöström, 1995). The validated McNeil-Sjöström scale (McNeil et al. 1994) includes several hundred items of potential harm to the fetus, each classified according to severity on an ordinal scale from 1 to 6 . In the present study, severe OCs were considered present in subjects who had experienced one or more complications of grade 5 or 6 , whereas subjects with complications of grade 4 and below were classified as not having had severe OCs. A complication of grade 5 is defined as 'potentially clearly greatly relevant/harmful' (e.g. severe pre-eclampsia or perinatal asphyxia), and a complication of grade 6 is defined as a complication that causes 'very great harm to or deviation in offspring' (e.g. eclampsia, offspring hypoxic-ischaemic cerebral injury). In addition, a diagnosis of perinatal asphyxia from the MBRN was recorded separately, to constitute a narrower hypoxic OCs parameter. By definition, all subjects recorded to have a diagnosis of asphyxia are classified as having severe OCs according to the McNeil-Sjöström scale. Birth-related variables are listed in Table 1.

\section{MRI acquisition}

All participants underwent MRI scanning on a $1.5 \mathrm{~T}$ Siemens Magnetom Sonata scanner (Siemens Medical Solutions, Germany) equipped with a standard head coil. Two sagittal T1-weighted magnetization-prepared rapid gradient echo volumes were acquired with the Siemens tfl3d1_ns pulse sequence (echo time $=3.93 \mathrm{~ms}$, repetition time $=2730 \mathrm{~ms}$, inversion time $=1000 \mathrm{~ms}$, flip angle $=7^{\circ}$, field of view $=24 \mathrm{~cm}$, voxel size $=1.33 \times$ $0.94 \times 1 \mathrm{~mm}^{3}$, number of partitions $=160$ ) and subsequently averaged together, after rigid-body registration, to increase the signal to noise ratio. There was no scanner upgrade during the study period, and patients and controls were scanned consecutively. A neuroradiologist evaluated all scans, and scans with brain pathol ogy were excluded.

\section{MRI post-processing}

FreeSurfer software (version 4.5.0) (http://surfer.nmr. mgh.harvard.edu) was used to obtain hippocampal, amygdala, ventricular and intracranial volumes (ICVs) from T1-weighted images (Fischl, 2012). Briefly, the 
Table 1. Demographic, clinical and birth-related characteristics

\begin{tabular}{|c|c|c|c|c|c|c|c|}
\hline & \multicolumn{2}{|c|}{ Psychotic BD $(n=48)$} & \multicolumn{2}{|c|}{ Non-psychotic BD $(n=31)$} & \multicolumn{2}{|c|}{ Control subjects $(n=140)$} & \multirow[b]{2}{*}{$p^{\mathrm{a}}$} \\
\hline & Mean (S.D.) & Range & Mean (S.D.) & Range & Mean (s.D.) & Range & \\
\hline Sex, $n(\%)$ & & & & & & & 0.024 \\
\hline Male & $23(48)$ & & $8(26)$ & & $74(53)$ & & \\
\hline Female & $25(52)$ & & $23(74)$ & & $66(47)$ & & \\
\hline Handedness, $n(\%)$ & & & & & & & 0.660 \\
\hline Right & $39(87)$ & & $28(90)$ & & $130(93)$ & & \\
\hline Left & $5(11)$ & & $3(10)$ & & $9(6)$ & & \\
\hline Ambidextrous & $1(2)$ & & $0(0)$ & & $1(1)$ & & \\
\hline Perinatal asphyxia, $n(\%)$ & & & & & & & 0.314 \\
\hline Yes & $9(19)$ & & $7(23)$ & & $18(13)$ & & \\
\hline No & $39(81)$ & & $24(77)$ & & $122(87)$ & & \\
\hline Severe OCs, $n(\%)$ & & & & & & & 0.209 \\
\hline Yes & $18(37)$ & & $9(29)$ & & $34(24)$ & & \\
\hline No & $30(63)$ & & $22(71)$ & & $106(76)$ & & \\
\hline Age, years & $29.9(6.7)$ & $19-42$ & $28.7(4.8)$ & $18-42$ & $30.8(6.1)$ & $18-42$ & 0.200 \\
\hline Gestational age, weeks & $39.7(2.4)$ & $31-44$ & $40.2(1.9)$ & $35-43$ & $39.9(1.8)$ & $35-45$ & 0.535 \\
\hline Maternal age, years & $28.0(4.7)$ & $18-39$ & $27.7(5.8)$ & $20-40$ & $27.3(4.8)$ & $18-40$ & 0.690 \\
\hline Birth weight, $g$ & $3570(623)$ & $1880-4900$ & $3523(456)$ & $2580-4560$ & $3518(528)$ & $2200-4990$ & 0.843 \\
\hline Birth head circumference, $\mathrm{cm}(n=103)$ & $35.4(1.4)$ & $32-38$ & $34.8(1.5)$ & $32-38$ & $35.3(1.4)$ & $32-38$ & 0.438 \\
\hline Duration of education, years & $13.6(2.3)$ & $9-20$ & $13.6(2.2)$ & $9-18$ & $14.1(2.2)$ & $9-20$ & 0.229 \\
\hline NART IQ & $106.2(4.1)$ & $97.6-114.2$ & $106.6(3.2)$ & $98.7-112.2$ & $107.0(3.7)$ & $97.7-114.7$ & 0.094 \\
\hline YMRS & $2.4(3.1)$ & $0-11$ & $2.4(2.8)$ & $0-8$ & & & 0.980 \\
\hline IDS & $15.6(13.0)$ & $0-50$ & $22.6(11.6)$ & $7-51$ & & & 0.021 \\
\hline GAF symptom & $57(11)$ & $35-80$ & $57(7)$ & $42-69$ & & & 0.951 \\
\hline GAF function & $53(14)$ & $31-82$ & $59(9)$ & $43-75$ & & & 0.063 \\
\hline PANSS positive & $10.2(3.6)$ & $7-25$ & $9.8(2.8)$ & $7-17$ & & & 0.775 \\
\hline PANSS negative & $10.7(4.0)$ & $7-25$ & $10.6(3.7)$ & $7-21$ & & & 0.867 \\
\hline Age at illness onset, years & $25.9(7.2)$ & $14-41$ & $24.7(5.2)$ & $16-38$ & & & 0.408 \\
\hline \multicolumn{8}{|l|}{ Medication, DDD ( $n=\mathrm{pBD} / \mathrm{npBD})$} \\
\hline Antipsychotics $(n=30 / 4)$ & $0.9(0.6)$ & $0.1-2.5$ & $0.6(0.3)$ & $0.5-1.0$ & & & 0.358 \\
\hline Antiepileptics $(n=21 / 17)$ & $0.8(0.4)$ & $0.7-1.3$ & $0.5(0.3)$ & $0.3-1.1$ & & & 0.064 \\
\hline Antidepressants $(n=20 / 13)$ & $1.5(0.8)$ & $0.3-3.0$ & $1.6(0.7)$ & $0.8-3.0$ & & & 0.794 \\
\hline Lithium $(n=8 / 4)$ & $1.1(0.4)$ & $0.5-1.8$ & $0.9(0.3)$ & $0.5-1.3$ & & & 0.587 \\
\hline
\end{tabular}

BD, Bipolar disorder; S.D., standard deviation; OCs, obstetric complications as scored by the McNeil Sjöström scale; NART IQ, NART National Adult Reading Test; YMRS Young Mania Rating Scale; IDS, Inventory of Depressive Symptomatology; GAF, Global Assessment of Function scale - split version; PANSS, Positive and Negative Syndrome Scale; DDD, defined daily dosage; pBD psychotic BD; npBD non-psychotic BD.

Data are given as number (percentage) or as mean (S.D.) and range.

a Analysed by $\chi^{2}$ for sex, handedness, perinatal asphyxia and severe OCs; otherwise analysis of variance.

subcortical segmentation algorithm combines information on image intensity, probabilistic atlas location, and the local spatial relationships between structures to automatically assign a neuroanatomical label to each voxel in the MRI volume (Fischl et al. 2002). The reliability of the automatic volume measurements has been tested against manual tracing, and the agreement between the automatically obtained volumes and manual tracings was comparable with the agreement between manual tracings obtained by two different experts (Fischl et al. 2002). The procedures were fully automated without manual editing. All scans were visually inspected following standard procedures.

\section{Statistical analyses}

All statistical analyses were performed within the statistical package SPSS version 20 (IBM SPSS Inc., USA). Group differences in demographic, clinical, obstetric and neurocognitive variables were analysed with Student's $t$ test and $\chi^{2}$ statistics. All statistical analyses were two-tailed. 
Table 2. Brain structure volumes (in $\mathrm{mm}^{2}$ ) in BD patients and healthy controls

\begin{tabular}{|c|c|c|c|c|}
\hline & Psychotic BD & Non-psychotic BD & Controls & Statistics ${ }^{\mathrm{a}}$ \\
\hline \multicolumn{5}{|c|}{ Amygdala } \\
\hline Left & $1722(210)$ & $1641(163)$ & $1695(223)$ & $F=0.69, p=0.693$ \\
\hline Right & $1736(217)$ & $1670(191)$ & $1718(241)$ & $F=0.43, p=0.958$ \\
\hline \multicolumn{5}{|c|}{ Hippocampus } \\
\hline Left & $4105(453)$ & $3934(384)$ & $4150(391)$ & $F=1.29, p=0.278$ \\
\hline Right & $4195(414)$ & $4064(386)$ & 4259 (419) & $F=1.09, p=0.339$ \\
\hline \multicolumn{5}{|c|}{ Lateral ventricles } \\
\hline Left & $8083(4649)$ & 7243 (4625) & 7364 (3833) & $F=1.42, p=0.245$ \\
\hline Right & $7463(4548)$ & $6756(4500)$ & $6924(3542)$ & $F=1.36, p=0.260$ \\
\hline
\end{tabular}

$\mathrm{BD}$, Bipolar disorder.

Data are given as mean (standard deviation).

${ }^{a}$ General linear model, diagnostic differences when age, sex, intracranial volume and lithium use are controlled for.

Diagnostic differences in brain volumes were assessed with a general linear model with the brain structure of interest as the dependent variable, diagnosis (psychotic bipolar disorder, non-psychotic bipolar disorder and healthy controls) as a fixed factor, and age, sex, ICVs and lithium use as covariates.

Hierarchical linear regression forced-entry models were used to study the associations between pre- and perinatal complications and brain structure within each diagnostic group, with the brain structure of interest as the dependent variable, and age, sex, and ICVs as independent variables entered in the first block, and perinatal asphyxia or severe OCs (both as dichotomous variables) in the second block. To adjust for multiple tests of brain volumes, Bonferroni correction was applied. Since the left and right hemisphere volumes were highly correlated (Pearson correlation, $r=0.84, p<0.0001$ for hippocampus; $r=0.80, p<0.0001$ for amygdala; $r=0.84, p<0.0001$ for the lateral ventricles), and the severe OCs/perinatal asphyxia categories were highly overlapping (all subjects with perinatal asphyxia were also classified as having severe OCs), the corrected threshold for statistical significance was set to 0.017 [0.05/3 brain structures (hippocampus, amygdala and lateral ventricles)]. Because lithium use is known to affect hippocampal and amygdala volumes (Hallahan et al. 2011), defined daily dosages (DDDs) of lithium were calculated according to the guidelines from the World Health Organization Collaborating Center for Drug Statistics Methodology (http://www.whocc.no/atcdd), and controlled for in the statistical analyses. DDDs were also calculated for antipsychotic medication, and preliminary analyses showed no association between either DDD or generation of antipsychotic medication to hippocampal/ amygdala/ventricular volumes. Moreover, including handedness as a covariate in the statistical model did not affect the results. Hence, handedness, and DDD and generation of antipsychotic medication were not included in the main statistical analyses.

\section{Results}

Demographic, clinical and birth-related variables

Demographic, clinical and birth-related characteristics are given in Table 1 . There were significantly more women in the non-psychotic bipolar disorder group $\left[\chi^{2}=7.74\right.$, degrees of freedom $\left.(\mathrm{df})=2, p=0.024\right]$ and patients with non-psychotic bipolar disorder had significantly more current depressive symptoms (higher scores on the IDS) than patients with psychotic illness $(F=5.54, \mathrm{df}=1, p=0.021)$. No other significant differences between groups were found. Noteworthy, patients with bipolar disorder and healthy controls did not differ in the prevalence of perinatal asphyxia $\left(\chi^{2}=2.11, \mathrm{df}=1, p=0.147\right)$ or severe OCs $\left(\chi^{2}=2.46\right.$, $\mathrm{df}=1, p=0.117)$. Within the bipolar group, subjects with psychotic and non-psychotic illness did not differ in the prevalence of perinatal asphyxia $\left(\chi^{2}=\right.$ $0.171, \mathrm{df}=1, p=0.679)$ or severe OCs $\left(\chi^{2}=0.600, \mathrm{df}=1\right.$, $p=0.438)$.

\section{Case-control differences in brain volumes}

Ventricular, hippocampal and amygdala volumes did not differ between patients with psychotic bipolar disorder, non-psychotic bipolar disorder and healthy controls, when age, sex, ICV and lithium use were controlled for (Table 2). Nor were there any significant differences in brain volumes between the whole bipolar disorder patient group (patients with psychotic and non-psychotic bipolar disorder combined) and healthy controls $(F=1.50, p=0.221$ for the left and $F=1.50, p=0.222$ for the right hippocampus; $F=0.75$, 
Table 3. Associations between severe OCs, perinatal asphyxia and brain structure volumes in patients with bipolar disorder $(n=79)$ and healthy controls $(n=140)^{\mathrm{a}}$

\begin{tabular}{|c|c|c|c|c|c|c|c|c|c|c|}
\hline & \multicolumn{5}{|c|}{ Severe OCs } & \multicolumn{5}{|c|}{ Perinatal asphyxia } \\
\hline & $t$ & $p$ & $\operatorname{adj} p$ & $B$ & (S.E.) & $t$ & $p$ & $\operatorname{adj} p$ & $B$ & (S.E.) \\
\hline \multicolumn{11}{|c|}{ Left hippocampus } \\
\hline Bipolar & -0.99 & 0.324 & 0.972 & -93.3 & $(94.0)$ & -1.00 & 0.319 & 0.957 & -114.6 & $(114.2)$ \\
\hline Controls & -0.17 & 0.866 & 1 & -10.8 & $(64.0)$ & 0.15 & 0.884 & 1 & 11.9 & $(81.8)$ \\
\hline \multicolumn{11}{|c|}{ Right hippocampus } \\
\hline Bipolar & -2.23 & 0.029 & 0.087 & -186.7 & $(83.9)$ & -1.59 & 0.117 & 0.351 & -164.3 & (103.6) \\
\hline Controls & 0.22 & 0.824 & 1 & 15.6 & $(70.0)$ & -0.09 & 0.929 & 1 & -7.9 & $(89.3)$ \\
\hline \multicolumn{11}{|c|}{ Left amygdala } \\
\hline Bipolar & -1.84 & 0.069 & 0.207 & -76.0 & $(41.2)$ & -2.57 & 0.012 & 0.036 & -126.1 & $(49.1)$ \\
\hline Controls & 1.36 & 0.177 & 0.531 & 49.9 & $(36.8)$ & 1.46 & 0.145 & 0.435 & 68.9 & $(47.0)$ \\
\hline \multicolumn{11}{|c|}{ Right amygdala } \\
\hline Bipolar & -0.65 & 0.521 & 1 & -30.7 & $(47.6)$ & -1.36 & 0.180 & 0.540 & -77.7 & $(57.3)$ \\
\hline Controls & 0.05 & 0.963 & 1 & 1.9 & $(41.2)$ & 0.90 & 0.372 & 1 & 47.1 & $(52.5)$ \\
\hline \multicolumn{11}{|c|}{ Left lateral ventricle } \\
\hline Bipolar & -0.48 & 0.631 & 1 & -743.8 & $(1012.5)$ & -0.33 & 0.744 & 1 & -404.6 & $(1234.1)$ \\
\hline Controls & 1.23 & 0.221 & 0.663 & 907.3 & $(710.5)$ & 0.22 & 0.842 & 1 & 204.0 & $(914.0)$ \\
\hline \multicolumn{11}{|c|}{ Right lateral ventricle } \\
\hline Bipolar & 0.56 & 0.574 & 1 & 315.5 & $(973.9)$ & 0.55 & 0.581 & 1 & 655.1 & $(1182.0)$ \\
\hline Controls & 1.18 & 0.242 & 0.726 & 975.6 & $(644.2)$ & 0.82 & 0.414 & 1 & 679.2 & $(828.8)$ \\
\hline
\end{tabular}

Severe OCs, Severe hypoxia-related obstetric complications; adj $p$, adjusted $p$ values after Bonferroni correction; S.E., standard error.

${ }^{a}$ Linear regression analyses controlled for effects of age, sex and intracranial volume within each diagnostic group.

$p=0.388$ for the left and $F=0.41, p=0.525$ for the right amygdala; $F=1.33, p=0.249$ for the left and $F=1.06$, $p=0.304$ for the right lateral ventricles).

\section{Associations between perinatal asphyxia, severe OCs and brain volumes}

Perinatal asphyxia was associated with smaller left amygdala volume $\left(t_{75}=-2.57, p=0.012\right)$ in bipolar disorder patients, but not in healthy controls $\left(t_{136}=1.46\right.$, $p=0.145)$, when age, sex and ICV were controlled for (Table 3). Including lithium use, gestational age and birth weight in the statistical model did not affect the results substantially, with asphyxia still being associated with smaller left amygdala volume $\left(t_{74}=-2.56\right.$, $p=0.012 ; t_{74}=-2.15, p=0.035 ;$ and $t_{74}=-2.56, p=0.013$, including lithium use, gestational age and birth weight, respectively). Severe hypoxia-related OCs were associated with smaller right hippocampal volume $\left(t_{75}=-2.25, p=0.029\right)$ in bipolar disorder patients but not in healthy controls $\left(t_{136}=0.223, p=0.824\right)$, an association that was stronger when lithium use was included in the model $\left(t_{74}=-2.40, p=0.019\right)$. This association did not remain significant after Bonferroni correction for multiple comparisons. No associations between asphyxia or severe OCs and the lateral ventricles were found in either patients with bipolar disorder or healthy control subjects.

When splitting the patients with bipolar disorder into patients with psychotic and non-psychotic disorder, patients with psychotic bipolar disorder showed distinct associations between perinatal asphyxia and smaller left amygdala volume $\left(t_{44}=-2.69, p=0.010\right)$, whereas patients with non-psychotic bipolar disorder showed smaller right hippocampal volumes related to both perinatal asphyxia $\left(t_{28}=-2.60, p=0.015\right)$ and severe OCs $\left(t_{28}=-3.25, p=0.003\right)$ (Table 4$)$. Hence, the amygdala findings in the whole group of patients with bipolar disorder appear to be driven by the patients with psychotic bipolar disorder, and the hippocampus findings by the patients with non-psychotic bipolar disorder. When lithium use, gestational age and birth weight were included in the statistical model, perinatal asphyxia was still associated with smaller left amygdala volume in patients with psychotic bipolar disorder $\left(t_{43}=-2.62, p=0.012 ; t_{43}=-2.47\right.$, $p=0.018$; and $t_{43}=-2.6, p=0.011$, including lithium use, gestational age and birth weight, respectively). In the non-psychotic bipolar disorder group, the association between perinatal asphyxia and smaller 
Table 4. Associations between severe OCs, perinatal asphyxia and brain structure volumes in patients with psychotic $(n=48)$ and non-psychotic $(n=31) B D^{\text {a }}$

\begin{tabular}{|c|c|c|c|c|c|c|c|c|c|c|}
\hline & \multicolumn{5}{|c|}{ Severe OCs } & \multicolumn{5}{|c|}{ Perinatal asphyxia } \\
\hline & $t$ & $p$ & $\operatorname{adj} p$ & $B$ & (S.E.) & $t$ & $p$ & $\operatorname{adj} p$ & $B$ & (S.E.) \\
\hline \multicolumn{11}{|l|}{ Left hippocampus } \\
\hline Non-psychotic BD & -2.49 & 0.019 & 0.057 & -386.2 & $(155.0)$ & -1.81 & 0.082 & 0.246 & -333.2 & $(178.0)$ \\
\hline Psychotic BD & -0.09 & 0.93 & 1 & -11.0 & (124.6) & -0.08 & 0.936 & 1 & -12.3 & $(153.2)$ \\
\hline \multicolumn{11}{|l|}{ Right hippocampus } \\
\hline Non-psychotic BD & -3.25 & 0.003 & 0.009 & -485.6 & $(149.5)$ & -2.60 & 0.015 & 0.045 & -449.0 & $(173.0)$ \\
\hline Psychotic BD & -0.77 & 0.445 & 1 & -82.4 & $(106.8)$ & 0.06 & 0.95 & 1 & 8.3 & $(132.2)$ \\
\hline \multicolumn{11}{|l|}{ Left amygdala } \\
\hline Non-psychotic BD & -1.19 & 0.244 & 0.732 & -85.6 & $(71.8)$ & -0.94 & 0.359 & 1 & -74.2 & $(79.4)$ \\
\hline Psychotic BD & -1.95 & 0.058 & 0.168 & -107.3 & $(55.1)$ & -2.69 & 0.010 & 0.030 & -175.5 & $(65.4)$ \\
\hline \multicolumn{11}{|l|}{ Right amygdala } \\
\hline Non-psychotic BD & -0.27 & 0.791 & 1 & -22.6 & $(83.0)$ & 0.30 & 0.764 & 1 & 27.5 & $(90.8)$ \\
\hline Psychotic BD & -1.15 & 0.257 & 0.771 & -72.8 & $(63.4)$ & -2.26 & 0.029 & 0.087 & -168.8 & $(74.9)$ \\
\hline \multicolumn{11}{|l|}{ Left lateral ventricle } \\
\hline Non-psychotic BD & 0.23 & 0.871 & 1 & 389.3 & $(1162.1)$ & -0.29 & 0.772 & 1 & -531.5 & $(1818.8)$ \\
\hline Psychotic BD & -1.65 & 0.107 & 0.321 & -2172.7 & $(1319.6)$ & -0.76 & 0.442 & 1 & -1288.1 & $(1661.5)$ \\
\hline \multicolumn{11}{|l|}{ Right lateral ventricle } \\
\hline Non-psychotic BD & 0.90 & 0.377 & 1 & 1303.2 & $(1450.6)$ & 0.52 & 0.610 & 1 & 827.9 & $(1604.6)$ \\
\hline Psychotic BD & -0.77 & 0.447 & 1 & -986.2 & $(1286.2)$ & -0.29 & 0.776 & 1 & -456.3 & (1590.9) \\
\hline
\end{tabular}

Severe OCs, Severe hypoxia-related obstetric complications; BD, bipolar disorder; adj $p$, adjusted $p$ values after Bonferroni correction; S.E., standard error.

${ }^{a}$ Linear regression analyses controlled for effects of age, sex and intracranial volume within each diagnostic group.

right hippocampus volume remained significant when DDDs of lithium use were included in the model $\left(t_{27}=-2.62, p=0.015\right)$, and was nominally significant when gestational age $\left(t_{27}=-2.15, p=0.042\right)$ and birth weight $\left(t_{27}=-2.44, p=0.022\right)$ were included in the model. The association between smaller right hippocampus volume and severe OCs also remained significant when DDDs of lithium use were included in the model $\left(t_{27}=-3.20, p=0.004\right)$. Worth noting, the associations between perinatal asphyxia/severe OCs and amygdala/hippocampus volume had the same direction in the opposite hemisphere structures, but these associations did not reach statistical significance (Table 4).

\section{Discussion}

We found that perinatal asphyxia and severe OCs were related to smaller amygdala and hippocampal volume in patients with bipolar disorder. Whereas patients with psychotic bipolar disorder showed reduced amygdala volume following perinatal asphyxia, patients with non-psychotic bipolar disorder showed reduced hippocampal volume following perinatal asphyxia and severe OCs, after adjustment for multiple comparisons, and controlling for the effects of age, sex, ICV and medication use. To the best of our knowledge, this is the first study to investigate associations between hypoxia-related pre- and perinatal complications and brain MRI morphometry in bipolar disorder.

Our findings indicate that perinatal hypoxic brain trauma is of importance for the adult brain morphology in bipolar disorder, and may thus be a neurodevelopmental factor of importance to disease development. This concurs to some extent with largescale epidemiological studies that report lower birth weight (Abel et al. 2010), specific OCs (Hultman et al. 1999) and premature birth (Nosarti et al. 2012) to increase the risk for bipolar disorder or affective psychosis. Indeed, we have in a subject sample overlapping with the current study previously demonstrated lower birth weight to correlate with smaller brain cortical surface area in patients across the psychosis spectrum as well as healthy controls (Haukvik et al. 2013). The results from the current study expand on this by demonstrating distinct associations between specific hypoxia-related pre- and perinatal complications and subcortical structures, known to be vulnerable to perinatal hypoxia (Carty et al. 2010; Morales et al. 2011), 
in patients with bipolar disorder. As such, the current findings to some extent support the speculation by Nosarti et al. (2012) that there may exist a neurodevelopmental subtype of bipolar disorder.

Within the whole group of bipolar disorder patients, we found perinatal asphyxia to be significantly associated with smaller left amygdala volume. The amygdala is involved in emotion processing and regulation, disturbances of which are core features of bipolar disorder (Townsend \& Altshuler, 2012). Altered amygdala function related to emotion-processing tasks has repeatedly been reported from functional MRI studies in patients with bipolar disorder (Cerullo et al. 2009). Emotional dysregulation and impaired stress response, other important features of bipolar disorder (Brietzke et al. 2012), may be caused by disturbances in corticotropin metabolism and dysfunction in the hypothalamic-pituitary-adrenal (HPA) axis (Gilmor et al. 2003; Spijker et al. 2009). Interestingly, a recent rat model study demonstrated significant long-term loss, shrinkage of cell soma size, and axonal degeneration of corticotropin-releasing factor-positive neurons in the amygdala following neonatal hypoxia-ischaemia (Carty et al. 2010). These changes were associated with increased locomotor activity and exploratory behaviour (Carty et al. 2010), behavioural abnormalities that are also observed in patients with bipolar disorder (Minassian et al. 2010; Perry et al. 2010). Moreover, increased anxiety has been reported following perinatal asphyxia and is associated with dopamine-innervated neurocircuitries in the amygdala, among other structures (Morales et al. 2011). Dopaminergic pathways are particularly vulnerable to perinatal asphyxia (Morales et al. 2011), and are also involved in the pathophysiology of psychotic disorders (Howes et al. 2009). Taken together, it seems biologically plausible that perinatal asphyxia is associated with long-term alterations in the structure of the amygdala, as our results suggest. Such alterations may be functionally associated with the distinct behavioural abnormalities observed in bipolar disorder.

Instead of confirming our initial hypothesis that the associations between perinatal asphyxia/severe OCs would be stronger in patients with psychotic than non-psychotic bipolar disorder, the results indicate different patterns of associations in psychotic versus non-psychotic bipolar disorder. Within a psychosis continuum, psychotic bipolar disorder would be considered to be closer than non-psychotic bipolar disorder to schizophrenia. In schizophrenia, smaller hippocampal volumes have been associated with preand perinatal trauma (van Erp et al. 2002; Schulze et al. 2003; Ebner et al. 2008). Surprisingly, we found no associations between severe OCs or perinatal asphyxia and smaller hippocampal volume in patients with psychotic bipolar disorder, but we did find such associations in patients with non-psychotic bipolar disorder. The biological validity of this association is, nevertheless, supported by the literature. First, animal models have demonstrated the pyramidal neurons within the hippocampus to be sensitive to prenatal hypoxia (Rees et al. 2008). Second, in the human neonate, hippocampal neurocircuitries are reported to be particularly vulnerable to hypoxia (Morales et al. 2011), and, third, healthy adolescents who have suffered perinatal asphyxia exhibit reduced hippocampal volumes (Maneru et al. 2003). Based on these findings, one could expect to find associations between perinatal hypoxia or severe OCs and hippocampal volume in the healthy controls as well, as we did in a previous study of schizophrenia patients and healthy controls (Haukvik et al. 2010). The hippocampus is, however, one of the brain regions in which neurogenesis occurs (Curtis et al. 2011), and the number of hippocampal neurons (Curlik \& Shors, 2013), as well as the hippocampal volume as measured by MRI (Pajonk et al. 2010), might increase in response to different training tasks. On the other hand, hippocampal volume may be reduced in alcohol dependence (Agartz et al. 1999; De Bellis et al. 2000) and heavy cannabis use (Cousijn et al. 2012), as well as in several mental disorders including schizophrenia (Adriano et al. 2012; Shepherd et al. 2012), unipolar depression (Arnone et al. 2012) and bipolar disorder (Hallahan et al. 2011; Hajek et al. 2012), although we did not confirm the latter in this study. As such, a variety of factors may confound and interfere with putative associations between pre- and perinatal trauma and adult hippocampal volume.

The number of possible known and unknown confounders not accounted for constitute one limitation in the current study. Although we did control for current lithium use, which is known to affect hippocampal and amygdala volumes in bipolar disorder, we did not have reliable data on cumulative medication use. Another possible limitation to the generalizability of the current study is the inclusion of patients across mood states, i.e. depression, mania/hypomania, and euthymia, since it has been suggested that amygdala volume may fluctuate across mood states (FolandRoss et al. 2012). Third, the subject groups were relatively small when the bipolar disorder group was split into psychotic and non-psychotic subgroups, which may have caused type II errors within the statistical analyses. Finally, by studying severe OCs, and comparing subjects with them versus all other subjects (including those with less severe OCs), we placed high demands on the strength of the relationship, and may have missed possible associations between 
brain structure and less severe OCs. Strengths of the current study include the use of unbiased birth registry data, thorough clinical characterization of participating subjects, and the use of one MRI scanner with no upgrades during the study period.

In summary, we report perinatal asphyxia to be related to smaller amygdala volume in patients with bipolar disorder. This suggests a neurodevelopmental component in the brain morphology of bipolar disorder. The different associations between preand perinatal complications and brain morphology observed in patients with psychotic and non-psychotic bipolar disorder, as well as their possible functional consequences, warrant further investigation.

\section{Acknowledgements}

We thank Thomas Bjella, Eivind Bakken and Martin Furan for technical assistance, and acknowledge the services of the Medical Birth Registry of Norway. The study was supported by grants from the Research Council of Norway (190311/V50, 167153/V50) and the South Eastern Norway Regional Health Authority (2008011, 2009037, 2011096). The funding organizations had no further role in study design, in the collection, analysis and interpretation of data, in the writing of the report, and in the decision to submit the paper for publication.

\section{Declaration of Interest}

A.M.D. is a founder and holds equity in CorTechs Labs, and also serves on the Scientific Board. The terms of this arrangement have been reviewed and approved by the University of California, San Diego, in accordance with its conflict of interest policies. O.A.A. has received speaker's honoraria from Lilly, Lundbeck and GSK in the last 2 years.

\section{References}

Abel KM, Wicks S, Susser ES, Dalman C, Pedersen MG, Mortensen PB, Webb RT (2010). Birth weight, schizophrenia, and adult mental disorder: is risk confined to the smallest babies? Archives of General Psychiatry 67, 923-930.

Adriano F, Caltagirone C, Spalletta G (2012). Hippocampal volume reduction in first-episode and chronic schizophrenia: a review and meta-analysis. Neuroscientist 18, 180-200.

Agartz I, Momenan R, Rawlings RR, Kerich MJ, Hommer DW (1999). Hippocampal volume in patients with alcohol dependence. Archives of General Psychiatry 56, 356-363.
Anticevic A, Brumbaugh MS, Winkler AM, Lombardo LE, Barrett J, Corlett PR, Kober H, Gruber J, Repovs G, Cole MW, Krystal JH, Pearlson GD, Glahn DC (2013). Global prefrontal and fronto-amygdala dysconnectivity in bipolar I disorder with psychosis history. Biological Psychiatry 73, 565-573.

Arnone D, Cavanagh J, Gerber D, Lawrie SM, Ebmeier KP, McIntosh AM (2009). Magnetic resonance imaging studies in bipolar disorder and schizophrenia: meta-analysis. British Journal of Psychiatry 195, 194-201.

Arnone D, McIntosh AM, Ebmeier KP, Munafò MR, Anderson IM (2012). Magnetic resonance imaging studies in unipolar depression: systematic review and meta-regression analyses. European College of Neuropsychopharmacology 22, 1-16.

Berretta S, Pantazopoulos H, Lange N (2007). Neuron numbers and volume of the amygdala in subjects diagnosed with bipolar disorder or schizophrenia. Biological Psychiatry 62, 884-893.

Bezchlibnyk YB, Sun X, Wang JF, MacQueen GM, McEwen BS, Young LT (2007). Neuron somal size is decreased in the lateral amygdalar nucleus of subjects with bipolar disorder. Journal of Psychiatry and Neuroscience 32, 203-210.

Brietzke E, Mansur RB, Soczynska J, Powell AM, McIntyre RS (2012). A theoretical framework informing research about the role of stress in the pathophysiology of bipolar disorder. Progress in Neuropsychopharmacology and Biological Psychiatry 39, 1-8.

Cannon TD, van Erp TG, Rosso IM, Huttunen M, Lonnqvist J, Pirkola T, Salonen O, Valanne L, Poutanen VP, Standertskjold-Nordenstam CG (2002). Fetal hypoxia and structural brain abnormalities in schizophrenic patients, their siblings, and controls. Archives of General Psychiatry 59, 35-41.

Carty ML, Wixey JA, Kesby J, Reinebrant HE, Colditz PB, Gobe G, Buller KM (2010). Long-term losses of amygdala corticotropin-releasing factor neurons are associated with behavioural outcomes following neonatal hypoxia-ischemia. Behavioural Brain Research 208, 609-618.

Cerullo MA, Adler CM, Delbello MP, Strakowski SM (2009). The functional neuroanatomy of bipolar disorder. International Review of Psychiatry 21, 314-322.

Cousijn J, Wiers RW, Ridderinkhof KR, van den Brink W, Veltman DJ, Goudriaan AE (2012). Grey matter alterations associated with cannabis use: results of a VBM study in heavy cannabis users and healthy controls. Neuroimage 59, 3845-3851.

Curlik DM 2nd, Shors TJ (2013). Training your brain: do mental and physical (MAP) training enhance cognition through the process of neurogenesis in the hippocampus? Neuropharmacology 64, 506-514.

Curtis MA, Kam M, Faull RL (2011). Neurogenesis in humans. European Journal of Neuroscience 33, 1170-1174.

De Bellis MD, Clark DB, Beers SR, Soloff PH, Boring AM, Hall J, Kersh A, Keshavan MS (2000). Hippocampal volume in adolescent-onset alcohol use disorders. American Journal of Psychiatry 157, 737-744. 
de Kieviet JF, Zoetebier L, van Elburg RM, Vermeulen RJ, Oosterlaan J (2012). Brain development of very preterm and very low-birthweight children in childhood and adolescence: a meta-analysis. Developmental Medicine and Child Neurology 54, 313-323.

Demjaha A, MacCabe JH, Murray RM (2012). How genes and environmental factors determine the different neurodevelopmental trajectories of schizophrenia and bipolar disorder. Schizophrenia Bulletin 38, 209-214.

Ebner F, Tepest R, Dani I, Pfeiffer U, Schulze TG, Rietschel M, Maier W, Traber F, Block W, Schild HH, Wagner M, Steinmetz H, Gaebel W, Honer WG, Schneider-Axmann T, Falkai P (2008). The hippocampus in families with schizophrenia in relation to obstetric complications. Schizophrenia Research 104, 71-78.

Edmiston EE, Wang F, Kalmar JH, Womer FY, Chepenik LG, Pittman B, Gueorguieva R, Hur E, Spencer L, Staib LH, Constable RT, Fulbright RK, Papademetris $X$, Blumberg HP (2011). Lateral ventricle volume and psychotic features in adolescents and adults with bipolar disorder. Psychiatry Research 194, 400-402.

Ellison-Wright I, Bullmore E (2010). Anatomy of bipolar disorder and schizophrenia: a meta-analysis. Schizophrenia Research 117, 1-12.

Engh JA, Friis S, Birkenaes AB, Jonsdottir H, Klungsoyr O, Ringen PA, Simonsen C, Vaskinn A, Opjordsmoen S, Andreassen OA (2010). Delusions are associated with poor cognitive insight in schizophrenia. Schizophrenia Bulletin 36, 830-835.

Fatemi SH, Folsom TD (2009). The neurodevelopmental hypothesis of schizophrenia, revisited. Schizophrenia Bulletin 35, 528-548.

Fischl B (2012). FreeSurfer. Neuroimage 62, 774-781.

Fischl B, Salat DH, Busa E, Albert M, Dieterich M, Haselgrove C, van der Kouwe A, Killiany R, Kennedy D, Klaveness S, Montillo A, Makris N, Rosen B, Dale AM (2002). Whole brain segmentation: automated labeling of neuroanatomical structures in the human brain. Neuron 33, 341-355.

Foland-Ross LC, Brooks JO 3rd, Mintz J, Bartzokis G, Townsend J, Thompson PM, Altshuler LL (2012). Mood-state effects on amygdala volume in bipolar disorder. Journal of Affective Disorders 139, 298-301.

Gilmor ML, Skelton KH, Nemeroff CB, Owens MJ (2003). The effects of chronic treatment with the mood stabilizers valproic acid and lithium on corticotropin-releasing factor neuronal systems. Journal of Pharmacology and Experimental Therapeutics 305, 434-439.

Hajek T, Kopecek M, Hoschl C, Alda M (2012). Smaller hippocampal volumes in patients with bipolar disorder are masked by exposure to lithium: a meta-analysis. Journal of Psychiatry and Neuroscience 37, 333-343.

Hallahan B, Newell J, Soares JC, Brambilla P, Strakowski SM, Fleck DE, Kieseppa T, Altshuler LL, Fornito A, Malhi GS, McIntosh AM, Yurgelun-Todd DA, Labar KS, Sharma V, MacQueen GM, Murray RM, McDonald C (2011). Structural magnetic resonance imaging in bipolar disorder: an international collaborative mega-analysis of individual adult patient data. Biological Psychiatry 69, 326-335.

Haukvik UK, Rimol LM, Roddey JC, Hartberg CB, Lange EH, Vaskinn A, Melle I, Andreassen OA, Dale A, Agartz I (2013). Normal birth weight variation is related to cortical morphology across the psychosis spectrum. Schizophrenia Bulletin. Published online 18 February 2013. doi:10.1093/schbul/sbt005.

Haukvik UK, Saetre P, McNeil T, Bjerkan PS, Andreassen OA, Werge T, Jonsson EG, Agartz I (2010). An exploratory model for $\mathrm{G} \times \mathrm{E}$ interaction on hippocampal volume in schizophrenia; obstetric complications and hypoxia-related genes. Progress in Neuropsychopharmacology and Biological Psychiatry 34, 1259-1265.

Haukvik UK, Schaer M, Nesvag R, McNeil T, Hartberg CB, Jonsson EG, Eliez S, Agartz I (2012). Cortical folding in Broca's area relates to obstetric complications in schizophrenia patients and healthy controls. Psychological Medicine 42, 1329-1337.

Howes OD, Egerton A, Allan V, McGuire P, Stokes P, Kapur S (2009). Mechanisms underlying psychosis and antipsychotic treatment response in schizophrenia: insights from PET and SPECT imaging. Current Pharmaceutical Design 15, 2550-2559.

Hultman CM, Sparen P, Takei N, Murray RM, Cnattingius S (1999). Prenatal and perinatal risk factors for schizophrenia, affective psychosis, and reactive psychosis of early onset: case-control study. British Medical Journal $318,421-426$.

Irgens LM (2000). The Medical Birth Registry of Norway. Epidemiological research and surveillance throughout 30 years. Acta Obstetricia et Gynecologica Scandinavica 79, 435-439.

Kempton MJ, Geddes JR, Ettinger U, Williams SC, Grasby PM (2008). Meta-analysis, database, and meta-regression of 98 structural imaging studies in bipolar disorder. Archives of General Psychiatry 65, 1017-1032.

Konradi C, Zimmerman EI, Yang CK, Lohmann KM, Gresch P, Pantazopoulos H, Berretta S, Heckers S (2011). Hippocampal interneurons in bipolar disorder. Archives of General Psychiatry 68, 340-350.

Liu L, Schulz SC, Lee S, Reutiman TJ, Fatemi SH (2007). Hippocampal CA1 pyramidal cell size is reduced in bipolar disorder. Cellular and Molecular Neurobiology 27, 351-358.

Maneru C, Serra-Grabulosa JM, Junque C, Salgado-Pineda $P$, Bargallo N, Olondo $M$, Botet-Mussons F, Tallada M, Mercader JM (2003). Residual hippocampal atrophy in asphyxiated term neonates. Journal of Neuroimaging 13, 68-74.

McNeil T, Sjöström K (1995). The McNeil-Sjöström Scale for Obstetric Complications. University Hospital, Department of Psychiatry: Malmö.

McNeil TF, Cantor-Graae E, Sjöström K (1994). Obstetric complications as antecedents of schizophrenia: empirical effects of using different obstetric complication scales. Journal of Psychiatric Research 28, 519-530.

McNeil TF, Cantor-Graae E, Weinberger DR (2000). Relationship of obstetric complications and differences in size of brain structures in monozygotic twin pairs 
discordant for schizophrenia. American Journal of Psychiatry 157, 203-212.

Minassian A, Henry BL, Geyer MA, Paulus MP, Young JW, Perry W (2010). The quantitative assessment of motor activity in mania and schizophrenia. Journal of Affective Disorders 120, 200-206.

Morales P, Bustamante D, Espina-Marchant P, Neira-Pena T, Gutierrez-Hernandez MA, Allende-Castro C, Rojas-Mancilla E (2011). Pathophysiology of perinatal asphyxia: can we predict and improve individual outcomes? EPMA Journal 2, 211-230.

Murray RM, Sham P, van OJ, Zanelli J, Cannon M, McDonald C (2004). A developmental model for similarities and dissimilarities between schizophrenia and bipolar disorder. Schizophrenia Research 71, 405-416.

Nosarti C, Reichenberg A, Murray RM, Cnattingius S, Lambe MP, Yin L, MacCabe J, Rifkin L, Hultman CM (2012). Preterm birth and psychiatric disorders in young adult life. Archives of General Psychiatry 69, E1-E8.

Pajonk FG, Wobrock T, Gruber O, Scherk H, Berner D, Kaizl I, Kierer A, Muller S, Oest M, Meyer T, Backens M, Schneider-Axmann T, Thornton AE, Honer WG, Falkai $P$ (2010). Hippocampal plasticity in response to exercise in schizophrenia. Archives of General Psychiatry 67, 133-143.

Perry W, Minassian A, Henry B, Kincaid M, Young JW, Geyer MA (2010). Quantifying over-activity in bipolar and schizophrenia patients in a human open field paradigm. Psychiatry Research 178, 84-91.

Peterson BS, Vohr B, Staib LH, Cannistraci CJ, Dolberg A, Schneider KC, Katz KH, Westerveld M, Sparrow S, Anderson AW, Duncan CC, Makuch RW, Gore JC, Ment LR (2000). Regional brain volume abnormalities and long-term cognitive outcome in preterm infants. Journal of the American Medical Association 284, 1939-1947.

Purcell SM, Wray NR, Stone JL, Visscher PM, O'Donovan MC, Sullivan PF, Sklar P (2009). Common polygenic variation contributes to risk of schizophrenia and bipolar disorder. Nature 460, 748-752.

Rapoport JL, Giedd JN, Gogtay N (2012). Neurodevelopmental model of schizophrenia: update 2012. Molecular Psychiatry 17, 1228-1238.

Rees S, Harding R, Walker D (2008). An adverse intrauterine environment: implications for injury and altered development of the brain. International Journal of Developmental Neuroscience 26, 3-11.

Rimol LM, Hartberg CB, Nesvåg R, Fennema-Notestine C, Hagler DJ Jr, Pung CJ, Jennings RG, Haukvik UK, Lange E, Nakstad PH, Melle I, Andreassen OA, Dale AM, Agartz I (2010). Cortical thickness and subcortical volumes in schizophrenia and bipolar disorder. Biological Psychiatry 68, 41-50.
Schulze K, McDonald C, Frangou S, Sham P, Grech A, Toulopoulou T, Walshe M, Sharma T, Sigmundsson T, Taylor M, Murray RM (2003). Hippocampal volume in familial and nonfamilial schizophrenic probands and their unaffected relatives. Biological Psychiatry 53, 562-570.

Shepherd AM, Laurens KR, Matheson SL, Carr VJ, Green MJ (2012). Systematic meta-review and quality assessment of the structural brain alterations in schizophrenia. Neuroscience and Biobehavioral Reviews 36, 1342-1356.

Simonsen C, Sundet K, Vaskinn A, Birkenaes AB, Engh JA, Faerden A, Jonsdottir H, Ringen PA, Opjordsmoen S, Melle I, Friis S, Andreassen OA (2011). Neurocognitive dysfunction in bipolar and schizophrenia spectrum disorders depends on history of psychosis rather than diagnostic group. Schizophrenia Bulletin 37, 73-83.

Spijker AT, van Rossum EF, Hoencamp E, DeRijk RH, Haffmans J, Blom M, Manenschijn L, Koper JW, Lamberts SW, Zitman FG (2009). Functional polymorphism of the glucocorticoid receptor gene associates with mania and hypomania in bipolar disorder. Bipolar Disorder 11, 95-101.

Spitzer RL, Williams JB, Kroenke K, Linzer M, deGruy FV, Hahn SR, Brody D, Johnson JG (1994). Utility of a new procedure for diagnosing mental disorders in primary care: The PRIME-MD 1000 study. Journal of the American Medical Association 272, 1749-1756.

Spitzer RL, Williams JBW, Gibbon M, First MB (1988). Structured Clinical Interview for DSM-III-R - Patient Version. Biometrics Research Department, New York State Psychiatric Institute: New York.

Strasser HC, Lilyestrom J, Ashby ER, Honeycutt NA, Schretlen DJ, Pulver AE, Hopkins RO, Depaulo JR, Potash JB, Schweizer B, Yates KO, Kurian E, Barta PE, Pearlson GD (2005). Hippocampal and ventricular volumes in psychotic and non-psychotic bipolar patients compared with schizophrenia patients and community control subjects: a pilot study. Biological Psychiatry 57, 633-639.

Townsend J, Altshuler LL (2012). Emotion processing and regulation in bipolar disorder: a review. Bipolar Disorder 14, 326-339.

van Erp TG, Saleh PA, Rosso IM, Huttunen M, Lonnqvist J, Pirkola T, Salonen O, Valanne L, Poutanen VP, Standertskjold-Nordenstam CG, Cannon TD (2002). Contributions of genetic risk and fetal hypoxia to hippocampal volume in patients with schizophrenia or schizoaffective disorder, their unaffected siblings, and healthy unrelated volunteers. American Journal of Psychiatry 159, 1514-1520. 